\title{
La disputada naturaleza jurídica de la declaración de pérdida de vigencia del permiso de conducción por extinción del saldo de puntos
}

\author{
Miguel Casino Rubio \\ Profesor Titular de Derecho Administrativo. Universidad Carlos III de Madrid \\ miguel.casino@tribunalconstitucional.es
}

\begin{abstract}
La entrada en vigor de la Ley 17/2005, de 19 de julio, siguiendo el ejemplo de los países de la Unión Europea, ha contribuido a reducir significativamente el índice de siniestralidad en las carreteras españolas. Esta ley propone un cambio decisivo en la comprensión tradicional del permiso de conducción y se refiere al grado de confianza que la sociedad otorga al interesado para conducir, y que la Ley cifra en un crédito expresado inicialmente, y a salvo de determinadas excepciones justificadas en el expediente personal de cada conductor, en la asignación de doce puntos. Este saldo se reduce por cada sanción firme en vía administrativa impuesta por la comisión de infracciones graves o muy graves, de acuerdo con un baremo previsto en la propia Ley, que determinan la pérdida de puntos en función de la gravedad de la infracción.
\end{abstract}

Palabras clave Jurisprudencia administrativa, Administración sancionadora, Tráfico, Circulación, Seguridad vial, Licencias, España.

\section{The controversial juridical nature of the declaration of loss of the driving licence for the extinction of balance of points}

\begin{abstract}
The current entry of the Law 17/2005, dated July 19, following the example of the countries of the European Union, has helped to reduce significantly the index of accidents in the Spanish roads. This law proposes a decisive change in the traditional comprehension of the driving licence and there refers to the confidence point that the company grants to the interested to drive, and that the Law codes in a credit expressed initially, and to except of certain exceptions justified in the personal process of every driver, in the assignment of twelve points. This balance diminishes for every firm sanction in administrative route imposed by the commission of serious or very serious infractions, of agreement with a scale in the own Law, which they determine the loss of points depending on the gravity of the infraction.
\end{abstract}

Key words

Administrative jurisprudence, sanctioning Administration, Traffic, Road Security, Licenses, Spain. 


\section{INTRODUCCIÓN}

A punto de cumplirse cuatro años de la entrada en vigor del denominado carné o permiso de conducción por puntos, introducido por la Ley 17/2005, de 19 de julio, siguiendo el ejemplo de los países europeos de nuestro entorno, es hoy ya communis opinio que su incorporación ha sido un acierto que ha contribuido a reducir significativamente el índice de siniestralidad.

El sistema es bien conocido. Parte de subrayar las trágicas consecuencias de las infracciones de tráfico y la consecuente necesidad de modificar los comportamientos infractores, particularmente de los conductores reincidentes. Con arreglo a este punto de partida, que no puede decirse que sea realmente nuevo, la Ley propone sin embargo un cambio muy decisivo en la comprensión tradicional del permiso o licencia de conducción.

En el nuevo esquema legal el popular carné de conducir no es ya sólo, ni siquiera principalmente, una licencia o autorización personal sujeta, como es norma en este tipo de intervención administrativa, a la comprobación del cumplimiento por el interesado de los requisitos de capacidad, conocimiento y habilidad necesarios para la conducción del correspondiente vehículo. Refiere sobre todo el grado de confianza que la sociedad otorga al interesado para conducir, y que la Ley cifra en un crédito expresado inicialmente, y a salvo de determinadas excepciones justificadas en el expediente personal de cada conductor, en la asignación de doce puntos.

Este saldo inicial aumenta o disminuye en función del posterior comportamiento del titular del permiso. Se reduce por cada sanción firme en vía administrativa impuesta por la comisión de alguna de las infracciones graves y muy graves que, de acuerdo con el baremo previsto en el anexo II de la propia Ley, determinan la pérdida de puntos, en una escala que varía en función de la gravedad de la infracción en cada caso considerada, y que comprende desde los dos a los seis puntos, con el límite máximo de ocho puntos por la acumulación de infracciones en un solo día, salvo que concurran determinadas infracciones muy graves, en cuyo caso el infractor perderá el número total de puntos que correspondan. Y se incrementa, hasta el límite máximo de quince puntos, por el transcurso de determinado número de años sin que el titular del permiso haya sido sancionado en firme en vía administrativa por alguna de esas mismas infracciones administrativas.

Cuando el titular consume el crédito de puntos de que dispone la Administración declara la pérdida de vigencia del premiso de conducción y el interesado, si quiere volver a conducir, debe obtener uno nuevo previa realización y superación con aprovechamiento de un curso de sensibilización y reeducación vial.

Éste es, grosso modo, el sistema ideado por la Ley y que, conforme al principio advertía, tan buenos resultados parece estar dando.

De todas formas no todo son parabienes. De hecho, en lo que ahora exclusivamente nos importa, no han faltado voces críticas que desde el primer momento han

254 combatido el comentado diseño del permiso de conducir por puntos, precisamente 
por el hecho de que la LTSV regule la detracción de puntos y la declaración de pérdida de vigencia del permiso de conducir en el Título IV de la Ley, relativo a las autorizaciones administrativas, y no, por tanto, dentro de su Título $\mathrm{V}$ dedicado a las infracciones y sanciones, como consideran que en buena técnica debiera haber sido, supuesto el carácter sancionador de las correspondientes medidas administrativas'.

Además de las razones que luego irán saliendo, esas críticas se han nutrido desde un principio de la propia confusión del Legislador, que ciertamente se ha manifestado en este punto con notable ambigüedad. Lo ha hecho, primero, en la exposición de motivos de la Ley 17/2005, cuando comienza destacando el carácter eminentemente reeducador del nuevo permiso por puntos para a renglón seguido subrayar el componente punitivo del sistema de detracción o pérdida del crédito en puntos del que dispone el conductor y sus consecuencias. Y también más tarde, en fecha mucho más reciente, con ocasión de la tramitación y aprobación de la nueva Ley 18/2009, de 23 de noviembre, por la que se modifica la LTSV en materia sancionadora. El texto del Proyecto de Ley remitido a las Cortes Generales modificaba el art. 67.5 LTSV para precisar que "no tienen el carácter de sanciones [...] la detracción de puntos como consecuencia de la imposición de sanciones firmes en vía administrativa”. Curiosamente, sin embargo, esta previsión, que parecía pensada precisamente para corregir la confusión de esas declaraciones iniciales, despareció a su paso por el Congreso sin dejar ningún rastro, dando pie a todo tipo de especulaciones.

De cualquier manera que sea, en este contexto se comprende mejor la polémica doctrinal y jurisprudencial acerca de la naturaleza jurídica de la pérdida de puntos y de la revocación que consideramos, en la que es fácil encontrar opiniones prácticamente para todos los gustos, y que a día de hoy dista bastante de haberse cerrado, menos aún en forma convincente, como enseguida podrá comprobarse.

\section{EL ESTADO DE LA CUESTIÓN EN LA DOCTRINA Y JURISPRUDENCIA ADMINISTRATIVAS}

En la doctrina científica hay, en primer lugar, quien opina que, pese al propósito más o menos confesado de la LTSV de excluir la pérdida de puntos y la declaración de pérdida de vigencia del permiso de conducir por extinción del crédito de puntos disponible del régimen sancionador, las citadas medidas son manifestación del ius puniendi del Estado y, por tanto, verdaderas sanciones administrativas.

Es el caso, por ejemplo, de Moreno Trapiella que, sirviéndose del modelo francés de permiso de conducir por puntos y de la jurisprudencia del Tribunal Europeo de

$1 \quad$ M. Arnaldo Fernández del Castillo, “El proyecto de reforma de la Ley sobre Tráfico en materia sancionadora y su integración en el ámbito local y europeo”, en el libro colectivo que recoge las ponencias presentadas en el I/ Foro nacional del derecho de la circulación, celebrado en Ciudad Real los días 19 y 20 de mayo de 2009, DGT, Madrid, 2010, pp. 9 y sigs. 
Derechos Humanos (STEDH, de 23 de septiembre de 1988, asunto: Malige c. Francia)2, concluye que la declaración administrativa de pérdida de vigencia del permiso de conducir como consecuencia de la comisión de las correspondientes infracciones es, en efecto, una resolución "de carácter sancionador", que además, en esa condición, pugna con la prohibición de bis in idem³.

Esta misma tesis, bien que con ciertos matices, es la que defiende Cano Campos. En opinión de este autor, que parte de notar el carácter ciertamente polémico del asunto y que reconoce incluso también la posibilidad de interpretar la declaración administrativa que consideramos como una revocación como consecuencia de la desaparición sobrevenida de los requisitos necesarios para su obtención, en línea con el criterio que luce en el art. 60.3 LTSV, son, sin embargo, "muchos y de más peso los argumentos que juegan a favor de [su] carácter sancionador" ". Con este propósito razona sobre el hecho de que la pérdida de puntos sea siempre consecuencia de la comisión de una previa infracción administrativa. Y subraya también el carácter constitutivo y el contenido aflictivo de la correspondiente resolución de la Administración, y que son justo las notas específicas de toda sanción administrativa. Para terminar advirtiendo que ésta es la tesis que igualmente parece seguir la jurisprudencia, con la STS de 4 de junio de 2009 a la cabeza y cuyo interés notaremos más adelante.

En paralelo no falta tampoco quien defiende en cambio que la detracción de puntos y la declaración administrativa de pérdida de vigencia del permiso de conducción por la pérdida del saldo total de puntos no son sanciones administrativas, sino la consecuencia inevitable de la desaparición sobrevenida de los requisitos necesarios para conducir. Esta es señaladamente la opinión, por ejemplo, de Santa-María Pérez, que, tomando pie en el art. 41 del anterior Reglamento General de Conductores de 1997, afirma que la revocación del permiso de conducir por la pérdida total de los puntos es la consecuencia ipso iure de la desaparición sobrevenida de la correspondiente aptitud, "en este caso de la sensibilidad al conducir, de la sumisión a la Ley de Tráfico, que asumió [al obtener] el permiso (...), y [desaparición] que prueba la sanción en firme de infracciones graves y muy graves"s.

2 La citada STEDH de 23 de septiembre de 1998 (caso Malige contra Francia), al hilo de determinar si la retirada de puntos es una "pena" y "una acusación en materia penal" a los efectos del art. 6.1 del Convenio, concluye que "aunque la medida de retirada [del permiso de conducir] presenta un carácter preventivo, reviste además un carácter punitivo y disuasorio y se parece por tanto a una pena accesoria" (\$39). Esta declaración, que es repetidamente invocada por quienes defienden la naturaleza sancionadora de la pérdida de puntos y de la declaración de pérdida de vigencia del permiso, está hecha sin embargo sin apenas pararse a argumentarla.

3 P. Moreno Trapiella, “Análisis de la regulación española del permiso de conducir por puntos y su confrontación con la jurisprudencia del Tribunal Europeo de Derechos Humanos”, Diario la Leyn. ${ }^{\circ} 6668$, de 9 de marzo de 2007, luego recogido en Revista jurídica Española la Ley, 2-2007, pp. 1567 y ss., que ahora sigo.

4 T. Cano Campos, "Tráfico: infracciones y sanciones", en el libro colectivo coordinado por B. Lozano Cutanda, Diccionario de sanciones administrativas, lustel, Madrid, 2010, p. 1130.

5 L. F. Santa-María Pérez, “Análisis jurídico de la pérdida de puntos y de la ineficacia sobrevenida del permiso o licencia de conducir por pérdida del saldo total de puntos asignado. Consecuencias ante la jurisdicción contencioso-administrativa", en II Foro nacional de derecho de la circulación, DGT, Madrid, 2010, pp. 109 y ss. La cita corresponde a la p. 113. 
También Rebollo Puig ${ }^{6}$, comentando brevemente la regla que por entonces establecía el citado art. 41 del Reglamento de 1997, y según la cual “en materia de conocimientos o comportamientos, podrá considerarse que existe una presunta desaparición de éstos cuando el titular de la autorización, durante el período de dos años, haya sido sancionado en firme en vía administrativa por la comisión de tres infracciones muy graves, sea cual sea el vehículo con el que se hubieran cometido", opina que la revocación del permiso por el indicado motivo no es ninguna sanción, aunque la pérdida sobrevenida del requisito exigible "se deduzca de la comisión de infracciones".

Algo más tibia es, finalmente, la posición de Huergo Lora que se limita a dar sumaria cuenta del criterio contrario al carácter sancionador que despunta en la LTSV, y en el que de todas formas aprecia una regla sobre la reincidencia que "se parece mucho" a la censurada por la STC 188/2005, de 4 de julio, y a dar noticia de la solución del Derecho alemán?.

\section{La lección de la jurisprudencia}

Parecida o igual división de opiniones puede verse si de la doctrina pasamos ahora a la jurisprudencia administrativa.

Aunque lleva fecha de hace tiempo y es incluso anterior a la puesta en marcha del permiso o licencia de conducir por puntos, la STS de 24 de mayo de 2001, bien parece en todo caso importante porque alude al mismo núcleo de problemas que ahora nos interesan.

Esta Sentencia resuelve el recurso promovido por la Asociación Automovilistas Europeos Asociados contra el Real Decreto 1110/1999, de 25 de junio, por el que se modificó el art. 41.2 del Reglamento General de Conductores (aprobado por Real Decreto 772/1997, de 30 de mayo), y que por entonces establecía que:

"En materia de conocimientos, aptitudes, habilidades o comportamientos podrá considerarse que existe una presunta desaparición de los mismos cuando el titular de la autorización durante el período de dos años, haya sido sancionado en firme en vía administrativa por la comisión de tres infracciones graves, o dos muy graves, o dos infracciones graves y una muy grave, sea cualquiera el vehículo con el que se hubieran cometido".

La Asociación recurrente afirmaba que esta regla pugnaba con lo dispuesto en el art. 82 LTSV, que obliga a cancelar los antecedentes en el plazo de seis meses desde su cumplimiento, y rezumaba arbitrariedad puesto que la revocación del permiso se justificaba en meras suposiciones o sospechas. También denunciaba que esa revocación era en realidad una sanción administrativa y, por tanto, que el Reglamento discu-

6 M. Rebollo Puig, “El contenido de las sanciones", en Infracciones, sanciones y procedimiento administrativo sancionador, Revista Justicia Administrativa, número extraordinario, 2001, pp. 199, por nota.

7 A. Huergo Lora, Las sanciones administrativas, lustel, Madrid, 2007, p. 339, por nota. 
tido había penetrado sin la imprescindible cobertura legal en el ámbito constitucionalmente reservado a la Ley.

El Tribunal Supremo desestimó el recurso haciendo especial hincapié en el carácter no sancionador de la revocación controvertida y en el hecho de que nada impide que "una conducta [infractora] reiterada pueda ser considerada como indiciaria de la pérdida de unos determinados conocimientos aptitudes, habilidades o comportamientos exigibles para la obtención y permanencia en la posesión de una licencia para conducir vehículos a motor". Pues, en materia de autorizaciones, "el control por la Administración se desarrolla de forma permanente (...), por cuanto las habilidades para conducir y los hábitos de comportamiento son algo que debe constatarse en el ejercicio diario de la conducción, no siendo apreciables de manera definitiva en un examen [o control previo]".

Aunque luego podrá verse todo esto con algo más de razón, adelanto ya que personalmente el razonamiento de esta Sentencia me parece impecable. Lamentablemente, en lo que conozco, ha tenido escasa repercusión. De hecho no figura ya en ninguna de las pocas sentencias de los Juzgados y Tribunales Superiores de Justicia que he podido consultar, ni es al cabo tampoco el criterio que parece defender hoy el propio Tribunal Supremo.

En la jurisprudencia menor hay en efecto contadas sentencias que abordan este asunto de la naturaleza jurídica de la declaración de pérdida de vigencia del permiso. Todas lo hacen, no obstante, para declarar el carácter sancionador de la medida. La Sentencia del Juzgado de lo Contencioso-Administrativo núm. 3 de Pamplona, de 9 de octubre de 2007, es sin duda la más detallada cuando afirma que:

"ciertamente la pérdida de puntos no aparece recogida en el elenco de sanciones del art. $67 \mathrm{LTSV}$, pero de ello no cabe deducir que no se trata materialmente de una sanción. De no entenderlo así, se llegaría al absurdo de considerar sanción la suspensión temporal del permiso de conducción, sí incluida en dicho precepto, y no, por ejemplo, la retirada total de puntos, que conlleva la pérdida de vigencia de la autorización para conducir (...). La propia Ley se refiere en su preámbulo al "efecto punitivo para aquellos comportamientos, consistente en la disminución o pérdida del crédito en puntos con que cuenta un conductor... [por su parte] la Sentencia del TEDH de 23 de septiembre de 1998 [caso Malige c. Francia] declara que si la medida de retirada de los puntos presenta un carácter preventivo, reviste igualmente un carácter punitivo y disuasorio, por lo que constituye una pena accesoria".

Parecido criterio luce en la Sentencia del TSJ de Madrid de 3 de diciembre de 2009, y que anula la pérdida de puntos recurrida porque en el caso considerado la Administración sólo informó al conductor de la multa a pagar por la infracción cometida, "pero no de la sanción accesoria de pérdida de puntos (... ), que [le] fue impuesta de plano violando el derecho de defensa"

8 Conste en todo caso que estas y otras declaraciones judiciales parecidas, como la que luce en la 258 STSJ de Madrid, de 4 de junio de 2009, están formuladas sin pararse mucho a intentar justificarlas. 
Estando el asunto en estas coordenadas, el Tribunal Supremo dicta la conocida Sentencia de 4 de junio de 2009, que ha sido aireada con júbilo por las asociaciones de automovilistas. En esta ocasión, el Tribunal resuelve el recurso directo promovido por la asociación Automovilistas Europeos Asociados contra el Real Decreto 62/2006, de 27 de enero, que modificó el Reglamento General de Conductores de 1997 para adecuarlo al permiso de conducir por puntos introducido por la Ley 17/2005. La asociación recurrente denunciaba, entre otros extremos, indefensión por no prever el Reglamento cuestionado un trámite de audiencia al interesado en el supuesto de pérdida parcial de puntos. Aunque la Sentencia desestima finalmente el recurso, advierte no obstante que

“pese a que la pérdida de puntos no aparece incluida en el catálogo de sanciones del artículo 67 LTSV, es indudable que la pérdida de puntos es una medida que tiene carácter materialmente sancionador. El que el descuento de los puntos no se haga efectivo sino cuando la sanción es firme no viene sino a confirmar la naturaleza sancionadora de la pérdida de puntos, pues es también después de la firmeza cuando se produce la anotación de sanción en el Registro de conductores e infractores. (...). Por ello, para que la aplicación de esta medida quede revestida de las garantías exigibles, enervando todo riesgo de indefensión, $[\mathrm{y}]$ aunque la norma reglamentaria no lo establece de forma expresa, es exigible que durante la tramitación del procedimiento sancionador el interesado quede cumplidamente informado de los puntos que podrá perder en caso de resultar sancionado; y asimismo es exigible que al notificarse al interesado la resolución sancionadora se le indique de forma clara la pérdida de puntos que llevará aparejada la sanción una vez que sea firme.

Y a lo dicho añade lo siguiente:

“Por las misma razones, y puesto que de otro modo podría producirse la indefensión a que alude la demandante, debe también afirmarse que en la impugnación que se dirija contra la resolución sancionadora podrán cuestionarse no sólo la conducta infractora y la cuantía de la sanción pecuniaria sino también la medida relativa a la pérdida de puntos y la correcta aplicación del Anexo-II de la Ley (...), siendo admisible que la impugnación se refiera sólo a ésta última cuestión. No ignoramos que, al afirmar que en la impugnación dirigida contra la resolución sancionadora puede combatirse la pérdida de puntos, se está contemplando la posibilidad de combatir una medida que todavía no se ha materializado, pues el descuento de los puntos sólo tiene lugar cuando la sanción es firme. Pero es indudable que la pérdida de puntos es una consecuencia directa y automática de la sanción, y participa de su misma naturaleza, por lo que debe quedar sujeta al mismo régimen de impugnación".

Según recordaba más arriba, algunos autores han visto en estas declaraciones la confirmación definitiva de la naturaleza sancionadora de las medidas administrativas que consideramos. En mi opinión, sin embargo, y frente a lo que sugieren y hasta afirman expresamente estas sentencias, el descuento de puntos o la declaración de pérdida de vigencia del permiso de conducir por la pérdida total de puntos no son ninguna sanción administrativa.

Para intentar aclarar todo esto importa ver lo que sucede, por ejemplo, con la revocación de las licencias de armas y de navegación aérea, y que he escogido, como 
podrá comprobarse, por su innegable paralelismo con el asunto que aquí particularmente nos interesa.

\section{LAS DENOMINADAS SANCIONES RESCISORIAS}

Según testimonia el libro de Huergo Lora, distinguir las Ilamadas sanciones rescisorias de las simples revocaciones de autorizaciones administrativas ha sido desde siempre caballo de batalla doctrinal. Entre otras razones por culpa de un Legislador sectorial que nunca se ha atenido a ningún criterio seguro y ha enturbiado el ordenamiento con supuestos de revocación de actos administrativos favorables tan heterogéneos entre sí que al final es muy fácil perderse. De todas formas, hay también unos pocos supuestos de revocación realmente pacíficos, sobre los que nunca ha habido discusión.

\section{La revocación del permiso de armas}

El vigente Reglamento de Armas, aprobado por Real Decreto 137/1993, de 29 de enero, después de afirmar la regla de que "nadie podrá llevar ni poseer armas de fuego en territorio español sin disponer de la correspondiente autorización [administrativa]", previene que

"La vigencia de las autorizaciones concedidas (...) estará condicionada al mantenimiento de los requisitos exigibles con arreglo a lo dispuesto en este Reglamento para su otorgamiento, pudiendo los órganos competentes para su expedición comprobar en cualquier momento tal mantenimiento y procediendo a revocarlas en caso contrario" (art. 97.5).

Para establecer seguidamente que,

“En ningún caso podrán tener ni usar armas, ni ser titulares de las licencias o autorizaciones correspondientes, las personas cuyas condiciones psíquicas o físicas les impidan su utilización, y especialmente aquellas personas para las que la posesión y el uso de armas representen un riesgo propio o ajeno" (art. 98.1).

Interpretando estas previsiones, que siguen por lo demás el mismo criterio que ya antes por su parte había establecido el Reglamento de 1981, la jurisprudencia del Tribunal Supremo ha declarado en forma unánime desde entonces que la revocación del permiso de armas concedido por pérdida de las condiciones psicofísicas que determinaron su otorgamiento nada tiene que ver con el Derecho administrativo sancionador. La Sentencia de 21 de abril de 1992, que invoca con este propósito algunas de las primeras decisiones, afirma que "no nos encontramos en presencia de un expediente sancionador", pues

“en los supuestos de autorización, renovación o revocación de permisos o licencias de armas nos encontramos ante actos administrativos encuadrables en las denominadas autorizaciones en [las] que la valoración de las circunstancias, hechos o datos 
concurrentes exige por razón del interés general, una atribución de facultad discrecional a favor de la autoridad competente, aunque tal facultad desde luego no supone una atribución de un poder arbitrario, al deber estar fundamentada en hechos, datos o circunstancias que supongan una modificación específicamente significativa de los requisitos subjetivos contemplados al concederse la autorización".

Este criterio está perfectamente resumido en la Sentencia de 14 de mayo de 1998, que declara que, al igual que sucede con la denegación de la licencia, siempre que la revocación de la previamente concedida

\begin{abstract}
"se base en el incumplimiento de los requisitos establecidos por el ordenamiento para el desarrollo de la actividad pretendida, no cabe afirmar que se esté ante una medida sancionadora, sino de simple aplicación del ordenamiento por parte de la Administración competente (...), que no permite ser titulares de las licencias a las personas para las que la posesión y uso de armas representa un riesgo propio o ajeno. No nos hallamos pues ante un supuesto de revocación-sanción, sino de revocación por incumplimiento de los requisitos exigidos para el otorgamiento de la licencia".
\end{abstract}

Las Sentencias de 20 de enero de 1996, 14 de octubre y 9 de diciembre de 1997, y 24 de octubre de 1998 se inscriben igualmente en esta misma línea jurisprudencial, cuando, prácticamente de consuno, subrayan que

"La denegación o revocación de un permiso o licencia de armas por desaparición de las condiciones que justifican su otorgamiento no es manifestación del derecho punitivo del Estado, sino un acto de control administrativo sobre la existencia o subsistencia de las circunstancias, aptitudes o condiciones exigibles para ser titular del premiso o licencia concedidos".

Para el Tribunal Supremo, de hecho, es tan claro que la revocación del permiso de armas por el motivo considerado no tiene carácter sancionador que en la jurisprudencia más reciente no hay ya ningún rastro de esa discusión. Si se repasa la jurisprudencia esta podrá verse enseguida que la controversia se ha traslado efectivamente de lugar y consiste simplemente ahora en comprobar si los motivos invocados por la Administración para acordar la revocación del permiso son suficientes y están además razonados.

Aunque los supuestos son muy variados y la jurisprudencia "marcadamente casuística", como reconocen las SSTS de 28 de enero de 2008 y 21 de mayo de 2009, para el Tribunal Supremo son datos o circunstancias que demuestran esa pérdida de las aptitudes psicofísicas y, en consecuencia, habilitan la revocación de la correspondiente licencia de armas por desaparición sobrevenida de sus requisitos, entre otros los siguientes: incumplir el deber de depositar el arma y, "portándola a la vista de terceros, dedicarse a recorrer locales de ocio y efectuar consumiciones alcohólicas hasta perder el conocimiento, recobrándolo después tirado en la calle y comprobando que le había desaparecido el arma, aunque días más tarde la recuperase" (STS de 21 de abril de 1992); "participar en peleas o discusiones privadas" con otros ciudada- 
nos para acabar "utilizando el arma de fuego autorizada", aunque sea para disparar al aire (SSTS de 20 de enero y 8 de noviembre de 1996); acreditar un "comportamiento violento o agresivo" (SSTS de 27 de noviembre de 2009 y de 22 de enero de 2010) o haber cometido infracciones penales o administrativas (de 12 de marzo de 2002, y de 8 de abril de 2008), que hablen a las claras de la agresividad y "peligrosidad social” del titular de la licencia (STS de 24 de octubre de 1998); o, en fin, "encontrase en tratamiento psicológico y para alcohólicos” (STS de 21 de mayo de 2009).

Aunque todos estos supuestos no sean desde luego idénticos al que ahora nos ocupa sí ilustran suficientemente en todo caso acerca del riesgo para la seguridad propia o ajena como criterio rector, que marca la pauta a seguir. En particular, de esta jurisprudencia importa retener ahora, de un lado, la amplia facultad de la Administración para apreciar en todo momento la desaparición sobrevenida de los requisitos exigibles y, de otro, la posibilidad de valorar a este propósito los antecedentes penales o sancionadores como indicio o demostración de la pérdida de la aptitud necesaria.

\section{La revocación de las licencias de piloto de aeronaves civiles}

Algo muy parecido sucede asimismo con las licencias de piloto de aeronaves civiles. El art. 11 del Real Decreto 270/2000, de 25 de febrero, por el que se determinan las condiciones para el ejercicio de las funciones del personal de vuelo de las aeronaves civiles, establece, bajo la rúbrica ?garantía de la seguridad aérea", que

“la Dirección General de Aviación Civil podrá limitar las atribuciones que confiera, suspender cautelarmente y, en su caso, revocar, previa audiencia al interesado, cualquier licencia, habilitación, autorización, aprobación o certificado mediante resolución motivada, fundada en razones de seguridad aérea debidamente acreditadas".

Inmediatamente el Sindicato Español de Pilotos de Líneas Aéreas (SEPLA), la Asociación Española de Pilotos Civiles y Comerciales y el Colegio Oficial de Pilotos de Aviación Comercial impugnaron por separado ante el Tribunal Supremo el citado precepto, siguiendo además en todos los casos el procedimiento especial para la protección de los derechos fundamentales de la persona, por considerar que la revocación de la licencia de piloto es una auténtica sanción administrativa y, por tanto, una previsión que no cumple con las exigencias de rango formal y de predeterminación normativa de las conductas ilícitas a que obliga el principio de legalidad de las sanciones administrativas que garantiza el art. 25.1 CE.

La Sentencia de 2 de diciembre de 2002, que resuelve el recurso interpuesto por el SEPLA y a la que simplemente siguen luego las Sentencias de 3 y de 10 de octubre de 2003, rechazó este planteamiento y negó que la revocación considerada sea una sanción administrativa. En concreto, el Tribunal Supremo, que tiene muy en cuenta la advertencia que luce en la STC 181/1990, de 15 de noviembre, sobre el criterio que

262 debe guiar la distinción entre revocación-sanción y simple revocación motivada por el 
incumplimiento de los requisitos exigibles y descargada de todo componente sancionador, comienza subrayando que

\begin{abstract}
"una de las finalidades principales que la Administración persigue al establecer los requisitos necesarios para obtener dicho título, es atender a las necesidades prioritarias de la seguridad aérea. Es innegable que los títulos de piloto, en sus diversas variedades (...), exigen unos conocimientos, instrucción, experiencia y aptitud psico-física que tiene entre sus objetivos, de manera fundamental, que la persona a quien se le encomienda la dirección y manejo de una aeronave civil no ponga en peligro la seguridad aérea, dado que del acertado desempeño de la función dependen intereses de gran importancia, y, en muchos casos, la conservación de vidas humanas".
\end{abstract}

Con arreglo a este punto de partida la citada Sentencia afirma seguidamente que,

\begin{abstract}
"si las licencias de piloto se conceden pues en atención principal, aunque no única, a preservar la seguridad aérea, resulta razonable y justificado que la Administración, cuando existan razones que ponen en peligro esa seguridad, debidamente acreditadas y motivadas, pueda limitar, suspender o, si es necesario, revocar las licencias concedidas, ya que se produce un supuesto de incumplimiento de uno de las condiciones esenciales que motivaron su concesión: estar debidamente garantizada, por medio de los requisitos establecidos para obtener el título de piloto, la seguridad aérea".
\end{abstract}

\title{
En consecuencia,
}

“las facultades que previene el artículo 11 del Real Decreto 270/2000 no constituyen una sanción administrativa y que, por tanto, dicho precepto no vulnera el artículo 25.1 CE. No existe aquí infracción alguna que sancionar. Las razones para la revocación o limitación pueden no derivar de ninguna conducta culpable del piloto. Pueden ser motivos objetivos, nacidos de las circunstancias concurrentes, que, al poner en peligro la seguridad aérea, determinan el ineludible deber de la Administración de tomarlos en cuenta y evitar sus graves consecuencias".

Por lo mismo, la Sentencia de 3 de octubre de 2003 precisa por su parte que el hecho de que el precepto impugnado no especifique los casos concretos de peligro para la seguridad aérea que habilitan la revocación de la licencia no supone infracción del principio de tipicidad de las infracciones, ni siquiera constituye en rigor ninguna irregularidad. Refiere por el contrario un supuesto más de utilización normativa de un concepto jurídico indeterminado, de modo que "la validez y conformidad con el ordenamiento de la [correspondiente] medida de revocación de la licencia dependerá de la adecuada justificación de las razones de seguridad aérea que [en cada caso] la Administración invoque" 9 .

9 En idéntico sentido se pronuncian las SSTS de 26 de septiembre de 2003, 10 de diciembre de 2004, 27 d junio de 2005, y 25 de enero de 2006. 


\section{Observaciones finales}

Me parece que las enseñanzas que proporcionan estos dos ejemplos son difíciles de discutir y han quedado suficientemente explicadas.

Primera, en los supuestos de ejercicio de determinadas actividades privadas, caracterizadas por su temible riesgo para la seguridad y la integridad de la vida de las personas, es perfectamente lógico que el ordenamiento extreme el rigor y sujete la concesión de la preceptiva licencia o autorización administrativa a estrictos y cualificados requisitos y aptitudes personales, de carácter físico y psíquico.

Segunda, en este tipo de supuestos, el cumplimiento de los correspondientes requisitos debe acreditarse no solo en el momento de la solicitud, sino también lógicamente durante toda la vigencia de la autorización concedida, de modo que la desaparición sobrevenida de esos requisitos habilita a la Administración para acordar la revocación de la licencia previamente concedida.

Tercera, esa revocación, al igual que sucede con la denegación administrativa por incumplimiento de los requisitos y condiciones exigibles, es simplemente una medida de aplicación del ordenamiento, descargada de todo componente sancionador. Por decirlo en la expresión normalizada que luce en buena parte de las sentencias consultadas, la revocación es entonces simple manifestación del imprescindible control administrativo sobre la subsistencia de las circunstancias, aptitudes y condiciones exigibles para ser titular del premiso o licencia concedidos.

Cuarta, la decisión de la Administración debe ser motivada y estar justificada en las particulares circunstancias de cada caso. En esta necesaria comprobación ad casum la Administración (o la norma) puede tomar en consideración conductas o condiciones psicofísicas que no sean susceptibles de reproche jurídico, pero también lógicamente, incluso con mayor razón, comportamientos ilícitos, siempre que en uno y otro caso guarden relación con las aptitudes o condiciones personales exigibles. Pues lo decisivo es siempre que la conducta personal considerada ponga razonablemente de manifiesto, con arreglo a máximas de experiencia o criterios lógicos, la existencia de un riesgo para la seguridad propia o de terceros, incompatible con el mantenimiento de la autorización concedida.

\section{FINAL SOBRE EL TRASLADO DE ESTAS ENSEÑANZAS AL ASUNTO CONSIDERADO}

Si trasladamos ahora el núcleo de estas conclusiones al asunto que particularmente nos interesa podrá verse enseguida que cuadran punto por punto con la decla264 puntos disponible. 
Para empezar, difícilmente cabe dudar del peso de la seguridad vial como fundamento de las normas de circulación y del permiso de conducir por puntos que establece la LTSV ${ }^{10}$. Además de las declaraciones que más adelante irán saliendo, está reconocido así expresamente en la exposición de motivos de la Ley 17/2005 cuando, con cierta dosis de grandilocuencia, comienza justo llamando la "atención sobre las gravísimas consecuencias que, para la seguridad vial y para la vida de las personas, tienen los comportamientos reincidentes en la inobservancia de las normas [de circulación], poniendo así en permanente riesgo el primero de los nuestros derechos fundamentales que es el derecho a la vida y a la integridad física y moral de los usuarios de las vías públicas". Y está dicho así también en el art. 59.1 LTSV cuando establece que "con objeto de garantizar la aptitud de los conductores para manejar los vehículos y la idoneidad de éstos para circular con el mínimo riesgo posible, la circulación de vehículos a motor (...) queda sometida al régimen de autorización administrativa previa".

Como tampoco es discutible, de otra parte, que la vigencia del permiso de conducción depende del mantenimiento de las correspondientes aptitudes psicofísicas para conducir, de modo que su desaparición sobrevenida habilita su revocación por parte de la Administración. El art. 63.3 LTSV es tajante al señalar que "la vigencia de las autorizaciones administrativas (...) estará subordinada a que se mantengan los requisitos exigidos para su otorgamiento".

Tomando pie en esta previsión y teniendo en cuenta que ciertamente ni la LTSV ni el reciente Reglamento General de Conductores, aprobado por Real Decreto $818 / 2009$, de 8 de mayo (en adelante RGC), incluyen entre los requisitos necesarios para obtener el permiso de conducir el de disponer de saldo de puntos, Cano Campos ha alertado sobre la inconsecuencia de considerar la declaración de perdida de vigencia del permiso de conducir por el motivo considerado como una simple revocación motivada por la desaparición sobrevenida de uno de sus requisitos. Sencillamente porque "la tenencia del saldo total de puntos no es un requisito exigido para obtener el permiso o licencia de conducción, sino una consecuencia de su otorgamiento: no es un prius sino un posterius. El saldo de puntos se obtiene, precisamente, cuando se otorga el permiso de conducir"'.

A mi entender este argumento tiene, sin embargo, bastante de artificial y es acaso la mejor prueba de la confusión que padecemos ${ }^{12}$. Pues no es disponer de crédito de puntos, sino obviamente reunir la oportuna aptitud psicofísica el requisito que

10 Por todos, vid. T. Cano Campos, El régimen jurídico-administrativo del tráfico. Bases históricas y constitucionales de intervención y sanciones, Civitas, $2^{\text {a }}$ Ed, Madrid, 2010, pp. 187 y ss.

11 T. Cano Campos, "Tráfico: infracciones y sanciones”, cit., p. 1130.

12 De hecho, así se lo parece incluso al propio autor citado que a renglón seguido admite que, conforme a esa interpretación, "la pérdida de puntos vendría a ser una suerte de "termómetro" que al llegar a un determinado nivel (la pérdida total de los mismos) indicaría que tal uso es del todo incorrecto y procede por tanto declarar la revocación o pérdida de vigencia de la autorización”. T. Cano Campos, op. cit., p. 1130. 
sobrevenidamente desaparece cuando el titular del permiso pierde el saldo total de puntos inicialmente asignado como consecuencia de la sucesiva comisión de determinadas infracciones graves o muy graves.

Es cierto que entre las aptitudes psicofísicas necesarias para obtener y conservar el permiso de conducir, y de las que hablan los arts. 7.1.d) y 43.2 RGC y detalla luego el anexo IV, no figura tampoco el criterio de no haber sido sancionado por las correspondientes infracciones que sumadas determinen finalmente la pérdida total del saldo de puntos. No obstante, teniendo en cuenta la función de garantía de la seguridad vial y de la vida de las personas que inspira la LTSV, y que antes he recordado, no hay ninguna duda de que los comportamientos infractores reincidentes, y probados por las correspondientes sanciones firmes en vía administrativa, comprometen seriamente la seguridad vial, que sí es un criterio expresamente previsto por el $\mathrm{RGC}^{13}$, y revelan en consecuencia una incapacidad sobrevenida para conducir sin riesgo para la vida propia o ajena.

La exposición de motivos de la Ley 17/2005 me parece que habla bien a las claras de lo dicho cuando, después de notar la necesidad de salir al paso de los comportamientos infractores reincidentes, advierte que la detracción de puntos y la declaración de pérdida de vigencia del permiso como consecuencia de la pérdida total de los puntos se produce

"por la reiterada vulneración de las reglas, que intentan poner el necesario orden en la circulación de vehículos y que sistemáticamente son ignoradas por algunos usuarios de la vía, generando riesgos a los que una sociedad como la nuestra debe hacer frente de forma severa. Tender a la reeducación, al convencimiento, a la asunción de actitudes de respeto hacia los derechos de todos y, en concreto, a ése tan próximo al derecho a la vida, como es el de la seguridad vial, deben ser los principios que inspiran el sistema".

Por decirlo en términos deliberadamente simples, en mi opinión, con la incorporación del denominado carné por puntos, y aun sin llegar a decirlo expresamente, la LTSV ha incluido la "peligrosidad" del conductor como requisito de aptitud para poder obtener el permiso de conducir. Lo único que sucede, bien se comprende, es que esa peligrosidad $y$, por tanto, la capacidad o no para conducir sin riesgo no puede verificarse ex ante al tiempo del otorgamiento del permiso, salvo a través de un inaceptable juicio de intenciones. Sencillamente, como es trivial, porque en ese momento la Administración desconoce el comportamiento del futuro conductor e ignora, por lo tanto, si el titular del permiso de conducir va a utilizarlo luego con riesgo o no para la seguridad del tráfico ${ }^{14}$.

13 Aunque por la razones dichas ni siquiera ello es en rigor necesario, el art. 43.2.m) RGC establece como cláusula de cierre de las circunstancias que revelan una incapacidad para conducir y, en consecuencia, justifican la revocación del permiso de conducción “cualquier afección no mencionada en los apartados anteriores que pueda suponer una incapacidad para conducir o comprometer la seguridad vial”. 266 del permiso que el interesado es, por las razones que sean, una persona peligrosa para la seguridad vial no 
Con otras palabras, en el momento de la concesión del permiso normalmente lo único que la Administración puede verificar es que el interesado reúne los conocimientos y las habilidades y aptitudes psicofísicas necesarias para conducir. Pero poco más. Pues la aptitud para conducir con respeto a la normas de circulación o negativamente, si se prefiere, para hacerlo sin riesgo o desprecio para la vida e integridad de las personas únicamente puede comprobarse una vez que el permiso ha sido ya otorgado, pues sólo entonces podrá la Administración verificar si el conductor autorizado, en principio presumidamente apto para conducir, utiliza el permiso de conducción de manera compatible con la seguridad vial.

En este contexto, los términos "crédito" y "confianza" que utiliza la exposición de motivos de la citada Ley 17/2005 para explicar el sistema del permiso por puntos que incorpora no son desde luego casuales y, de hecho, me parece que explican muy bien el verdadero significado de la revocación que consideramos. Con la concesión del permiso de conducir la Administración deposita en el interesado la confianza, de la que por entonces no hay ninguna razón para dudar, de que lo utilizará para conducir con respeto a las normas y, sobre todo, sin riesgo para la seguridad vial. Una confianza que la Ley cifra en un determinado crédito de puntos, que desminuye o aumenta en función de su propia conducta, y que puede desaparecer por completo cuando el conductor ha demostrado un reiterado comportamiento infractor.

Esta técnica normativa nada tiene por otra parte de irregular y ni siquiera, para decir toda la verdad, es nueva en el panorama jurídico administrativo. Sucede siempre que la aptitud personal para el ejercicio de la actividad privada pretendida es relevante para la seguridad y la vida de las personas y no puede ser comprobada de forma inmediata y definitiva en el momento del otorgamiento de la correspondiente autorización, sino que exige un control permanente y a posteriori por parte de la Administración. Por esta razón, al igual que sucede con el uso de las armas o con la licencia de piloto de aeronaves que antes hemos visto, cuando la Administración dispone de pruebas o indicios razonables que demuestran una conducta peligrosa para la seguridad vial debe revocar la autorización previamente concedida, justamente en garantía de la imprescindible seguridad ${ }^{15}$.

Ni qué decir tiene también que el Legislador puede válidamente remitir esa comprobación de pérdida de la aptitud personal para conducir sin riesgo al juicio discrecional de la Administración o decidir también objetivar esos indicios y determinar por sí mismo, agotadoramente o no, las circunstancias o condiciones que revelan peligro-

dudaría en denegar su concesión por incumplimiento de los requisitos de aptitud personal necesarios. Cfr., M. Rebollo Puig, “El contenido de las sanciones....", cit., p. 198.

15 Como bien ha notado con carácter general M. Rebollo Puig ("el contenido de las sanciones" cit., p. 198), todo este tipo "de revocaciones no sancionadoras recaen sobre autorizaciones que, si se pidieran en el momento de la revocación, podrían y deberían ser denegadas por la Administración porque, por la razón que sea, se considera ahora que ya no es compatible con los intereses públicos protegidos con esa autorización". 
sidad y habilitan en consecuencia la revocación ${ }^{16}$. Como también me parece incontrovertible que, de seguir esta última opción, la Ley puede tomar en consideración tanto hechos o circunstancias irreprochables jurídicamente, como es el caso de los trastornos mentales y de conducta o relacionados con la adicción a drogas, estupefacientes o bebidas alcohólicas [art. 43.2. j) y k) RGC], como los antecedentes infractores del titular del correspondiente permiso o licencia.

Y todo esto es lo que cabalmente hace la LTSV. Atribuye a cada conductor autorizado un crédito de puntos, reflejo, como aclara la propia Ley, del nivel de confianza que como tal conductor le otorga la sociedad en el momento de la concesión del permiso y, a continuación, arbitra un mecanismo de comprobación del mantenimiento de esa confianza y, en consecuencia, de la aptitud para conducir. Que al hacerlo se haya fijado en los antecedentes infractores del conductor, y que funcionan además como causa automática de la declaración de pérdida de vigencia del permiso, nada tiene tampoco de extravagante, ni pugna asimismo con la prohibición de bis in idem o de castigar la reincidencia.

De un lado, porque conducir con infracción grave y reiterada de las normas de circulación es obviamente una conducta vial peligrosa y, por tanto, incompatible llegado el caso con la conservación del permiso de conducir para poder continuar haciéndolo poniendo en riesgo la seguridad del tráfico. $Y$ de otro, porque una cosa es que los antecedentes sancionadores no puedan ser tenidos en cuenta para tipificar o integrar una nueva infracción, que es el supuesto que enjuicia la STC 188/2005, de 4 de julio, citada por HUERGO LORA ${ }^{17}$, y otra muy distinta que no puedan serlo como indicio (rectius demostración, en nuestro caso) de la pérdida de la aptitud para conducir con arreglo a elementales pautas de comportamiento.

Incluso habría que añadir que la LTSV ha demostrado en este extremo una razonable y lógica prudencia, en línea con las experiencias comparadas. Pues la conclusión de la desaparición sobrevenida de la aptitud legal necesaria para conducir y, por tanto, la consecuente declaración de pérdida de vigencia del permiso no es el resultado de la sanción de una única infracción, por muy grave que sea, sino la consecuencia de varias sanciones.

Es probable que el Legislador haya pensado que, por más que las consecuencias de la conducción de vehículos pueden ser tanto o más dramáticas que en el caso, por seguir con los ejemplos antes propuestos, del uso de las armas de fuego o de la navegación aérea, conducir un vehículo es una conducta tan cotidiana y estrechamente vinculada al ejercicio de libertades y derechos fundamentales ${ }^{18}$ que no basta cometer

16 Cfr., en este sentido, L. F. Santa-María Pérez, “Análisis jurídico de la pérdida de puntos...”, op. cit., pp. 111 y 114 .

17 A. Huergo Lora, Las sanciones administrativas, cit., p.339, por nota.

18 T. Cano Campos, El régimen jurídico administrativo del tráfico..., op. cit., pp. 176 y ss. En parecido 268 sentido la STEDH de 23 de septiembre de 1998 (caso Malige c. Francia), citada en el texto, advierte que “el 
una infracción para poder concluir razonablemente que el conductor ha perdido la necesaria aptitud para hacerlo con la imprescindible seguridad. Seguramente también porque, con la Ley en la mano, son tantas las infracciones que se cometen todos los días, a veces incluso de forma inevitable, que el riesgo de que por esa vía todos los ciudadanos acabemos perdiendo el permiso es un precio demasiado alto, que el Legislador no ha querido pagar.

La jurisprudencia no en vano ya lo había notado en alguna ocasión. Valga como ejemplo la STS de 26 de febrero de 1992, cuando advierte que:

“El hecho escueto constitutivo de una transgresión de preceptos del Código de la Circulación, determinante de la causación de un accidente de tráfico, no supone por sí mismo la pérdida de dichas aptitudes legales o del conocimiento de las normas viarias pues, de lo contrario, cualquier persona sancionada por alguna infracción de tráfico del Código de la Circulación podría automáticamente y de modo inmediata ser privada por [la Administración] correspondiente de la habilitación para conducir".

Para añadir más adelante que

\begin{abstract}
"las causas productoras del [accidente] podrían ser constitutivas si así se apreciara en el correspondiente enjuiciamiento penal y tras al prueba pertinente del delito o falta específicamente tipificado o, en su caso, de una infracción administrativa declarada tras el adecuado procedimiento sancionador, pero de ellas repetimos no se deduce la carencia de las aptitudes legales o conocimientos de las normas esenciales para la seguridad de la circulación”'19.
\end{abstract}

En el mismo sentido, ya antes, la STS de 27 de octubre de 1981 había censurado la intervención administrativa inmediata del permiso de conducir del recurrente, que había causado un grave accidente de circulación, por considerar precisamente que si bien, al hacerlo, el conductor infringió varios preceptos del Código de la Circulación, esa infracción

\footnotetext{
"no se equipara al desconocimiento total de las normas esenciales para la seguridad de la circulación, ni la carencia o pérdida de las aptitudes físicas, psíquicas o técnicas para conducir".
}

Conste finalmente que la LTSV podía haber sido desde luego más clara en este punto y justificado algo mejor la lógica del sistema. Pues, a falta de la necesaria expli-

\footnotetext{
derecho a conducir un vehículo a motor es de gran utilidad para la vida corriente y el ejercicio de una actividad profesional" (\$39).

19 En parecidos términos, bien que a propósito ahora de la revocación del permiso de armas, la STS de 12 de febrero de 2008, advierte que para poder acordar justificadamente la revocación del permiso concedido "se ha de estar no a hechos aislados y puntuales sino a la secuencia de lo ocurrido en el tiempo".
} 
cación, no faltará seguro quién piense que todas las razones que hemos visto son un simple ardid con el que enredar las cosas y rebajar de contenido sancionador a la revocación del permiso que consideramos. Incluso más: que por esa vía, esto es, mediante el simple expediente de incorporar el correspondiente régimen sancionador (rectius: el cuadro de infracciones) a la nómina de requisitos necesarios para el otorgamiento de la preceptiva autorización, se corre el riesgo de acabar metiendo todo el Derecho administrativo sancionador en el saco de las revocaciones por desaparición sobrevenida de las condiciones y neutralizando, de paso, todo el arsenal de garantías vinculadas al ius puniendi.

Aunque algo de razón hay en estas posibles objeciones, el reproche que se comenta no puede ser de todas formas tampoco muy severo. Primero, porque las llamadas sanciones rescisorias y, general, la determinación de la naturaleza jurídica que mejor conviene a la revocación de actos administrativos favorables es una cuestión realmente complicada, que ha sido desde siempre objeto de controversia doctrinal y jurisprudencial, y que a día de hoy dista bastante de haber quedado definitivamente perfilada entre nosotros. $Y$ segundo porque, antes que el silencio o las vacilaciones de la Ley, lo que realmente despunta en este asunto es la pretensión de los automovilistas de extremar al máximo, cueste lo que cueste, las garantías del conductor infractor, incluso a pesar o en contra del significado interés general que defienden la LTSV y la Administración, y de los miles de conductores que cumplen escrupulosamente con la Ley.

\section{BIBLIOGRAFÍA}

M. Arnaldo Fernández del Castillo, "El proyecto de reforma de la Ley sobre Tráfico en materia sancionadora y su integración en el ámbito local y europeo", en el libro colectivo que recoge las ponencias presentadas en el /l Foro nacional del derecho de la circulación, celebrado en Ciudad Real los días 19 y 20 de mayo de 2009, DGT, Madrid, 2010.

T. Cano Campos, "Tráfico: infracciones y sanciones", en el libro colectivo coordinado por B. Lozano Cutanda, Diccionario de sanciones administrativas, lustel, Madrid, 2010.

- El régimen jurídico-administrativo del tráfico. Bases históricas y constitucionales de intervención y sanciones, DGT-Civitas, Madrid, 1999.

A. Huergo Lora, Las sanciones administrativas, lustel, Madrid, 2007.

P. Moreno Trapiella, “Análisis de la regulación española del permiso de conducir por puntos y su confrontación con la jurisprudencia del Tribunal Europeo de Derechos Humanos", Diario la Leyn. ${ }^{\circ} 6668$, de 9 de marzo de 2007, luego recogido en Revista jurídica Española la Ley, 2-2007.

M. Rebollo Puig, “El contenido de las sanciones", en Infracciones, sanciones y procedimiento administrativo sancionador, Revista Justicia Administrativa, número ex$270 \quad$ traordinario, 2001. 
L. F. Santa-María Pérez, "Análisis jurídico de la pérdida de puntos y de la ineficacia sobrevenida del permiso o licencia de conducir por pérdida del saldo total de puntos asignado. Consecuencias ante la jurisdicción contencioso-administrativa", en II Foro nacional de derecho de la circulación, DGT, Madrid, 2010.

Recibido: 21 de junio de 2010

Aceptado: 26 de julio de 2010 
